\title{
Diseño y construcción de un equipo de registro y análisis de potenciales evocados somatosensoriales de la médula espinal - Revisáo Aberta
}

\author{
Valeria Sella*
}

\section{RESUMO}

O resumo não está adequadamente distribuído. A introdução é longa e consome várias linhas. A pergunta clínica parece ter sido transformada em sentença, com proposta de descrição de um equipamento de baixo custo. A metodologia descreve apenas o equipamento em si, sem sequer citar pesquisa de campo com indivíduos para comprovar o funcionamento do equipamento apresentado. Não são citados resultados obtidos com testes mas o autor conclui que o equipamento seria muito útil para as áreas clínica e cirúrgica.

Unitermos: bioinstrumentação não consta no DECs

\section{INTRODUÇÃO}

O tema é interessante e pouco conhecido. Uma definição geral mais detalhada a respeito dos potenciais evocados, como potenciais elétricos produzidos por uma estimulação nervosa periférica ou sensorial registrados ao longo do trajeto neuronal e da área cerebral representativa ${ }^{1,2}$, forneceria ao leitor uma representação da importância do assunto. O autor poderia introduzir o tema com a definição e esclarecimento a respeito dos subtipos de potenciais evocados: visuais(PEV), auditivos e somatossensoriais ${ }^{3-6}$. Isso poderia facilitar a leitura para aqueles profissionais que não dominam a técnica de potencial evocado e fazer o leitor compreender a facilidade que o uso de estímulos elétricos pode trazer. O próprio autor explica as dificuldades para lidar com os potenciais medulares, que possuem baixa amplitude e ruídos que alteram ou confundem o sinal. O assunto Está bem exposto quanto aos conceitos do uso do potencial evocado para as cirurgias de coluna e sua importância, mas não cita possíveis diferenças de sinal em situações onde há a presença de patologias que geram a necessidade de uma cirurgia.

A argumentação do trabalho segue a linha de custo do equipamento, que deve ser levada em consideração em países em desenvolvimento. $\mathrm{O}$ autor não cita se a técnica é dominada por profissionais destes mesmos países, o que poderia ser explorado apresentando uma pesquisa de campo em seu país ou dados estatísticos que possam esclarecer este ponto e reforçar a defesa do texto. Náo há hipótese clara a respeito da intenção do estudo. No último parágrafo da introdução o autor declara que este artigo é a descrição do desenho e construção de um equipamento para mensurar potencias evocados somatosensoriais, durante procedimentos cirúrgicos medulares a baixo custo. No entanto, como se verá mais à frente, a conclusão do autor vai mais à frente, recomendando o uso do equipamento na área cirúrgica.

\section{MÉTODO}

As explanações sobre os módulos de hardware e software são ricas em detalhes; no entanto podem tornar-se confusas para aquele leitor sem conhecimentos específicos na área de engenharia. A inserção de figuras com esquemas sobre a construção do aparelho facilita a compreensão do processo de construção mas é neces-

* Fisioterapeuta, Setor de Neuro-Sono da Universidade Federal de São Paulo - Unifesp; mestrado em ciências (ênfase em engenharia biomédica) - CEFET-pr, São Paulo-SP, Brasil. 
sário ser compreendida pelo dito leitor.

Chama a atenção a falta de critérios de inclusão e exclusão no estudo. Além disso, a pesquisa de campo foi realizada em apenas um indivíduo, considerado saudável.

A área de saúde é ampla e muitos dos profissionais que nela atuam não tiveram contato com disciplinas pertencentes à graduação em engenharia; assim sendo poderiam ser mostrados os parâmetros práticos de uso, suprimindo alguns dados que atrasam a leitura do protocolo clínico. Cabe ressaltar a preocupação do autor com respeito a filtragem do sinal adquirido, com inclusão de filtros notch para tornar o equipamento menos susceptível aos sinais externos, já que a mais importante fonte de interferência na monitorização de sinais biomédicos é decorrente da rede de alimentação com linhas de força associadas a campos elétricos e magnéticos distribuídas por todo o ambiente. Esses campos elétricos podem interferir até quando os instrumentos estáo desligados, sendo necessário haver circulação de corrente para haver campo elétrico ${ }^{7}$.

Poderiam ser explorados aspectos da utilizaçáo do equipamento para o dia a dia, tornando o equipamento mais prático e menos acadêmico, já que o público alvo nem sempre domina a compatibilidade entre software e os diversos sistemas operacionais utilizados atualmente, ou mesmo a probabilidade de armazenamento dos dados obtidos em arquivos para comprovaçáo de uso ou para atualizaçáo da ficha clínica de cada paciente. Apesar da extensa apresentação do equipamento não houve detalhamento a respeito dos eletrodos utilizados. $\mathrm{O}$ autor relata apenas que os mesmos eram auto-adesivos para eletrocardiografia e o não são relatados métodos de preparo do paciente para a colocação dos eletrodos. $\mathrm{O}$ autor não esclareceu se o equipamento só pode ser utilizado com esse tipo de eletrodo ou se poderiam ser usados quaisquer eletrodos auto-adesivos. $\mathrm{O}$ fato permite ao leitor imaginar qual seria o fator determinante do uso: o tamanho, a fixaçáo, o agente condutor ou talvez o custo e facilidade para aquisição dos mesmos.

A escolha do eletrodo e o correto preparo do paciente são fatores de vital importância para a aquisição de sinais elétricos; a não consideração destes fatores algumas vezes compromete o estudo ou mesmo altera os resultados obtidos. As manobras para limpeza e colocação dos eletrodos são importantes para reduzir os artefatos que alteram o sinal adquirido que terminam por enfatizar suas propriedades elétricas. A impedância, citada desde a introdução do estudo, inclui a resistência ôhmica, a resistência capacitativa (ou reactância) e a resistência indutiva. Esta última é insignificante nos tecidos mas as duas primeiras exercem influência importante nos efeitos atuantes nos tecidos ${ }^{2}$. Eletrodos de superfície apresentam melhor performance em estudos do movimento humano, em biomecânica ou em aplicaçôes clínicas por serem não-invasivos, por não comprometerem o deslizamento da tela subcutânea, fáscias musculares e outros tecidos e por apresentarem sinais mais reprodutíveis que aqueles obtidos através de eletrodos de agulha ${ }^{8,9}$.

Inicialmente o protocolo clínico mostrou-se detalhado, sugerindo pela primeira vez no texto haver consideraçôes éticas já que cita que o indivíduo testado assinou um termo de consentimento livre e esclarecido; no entanto, há várias dúvidas que, se sanadas, esclareceriam melhor os procedimentos adotados. Por exemplo: Parece-nos importante ressaltar a realização do teste em um individuo são quando o próprio autor afirma que "La adquisición continua o seriada intraoperatoria de los PES constituye un procedimiento obligado en cirugías de columna vertebral o en aquellas donde potencialmente pueda verse afectada la médula espinal... El costo comercial del equipo requerido para el uso clínico de los PES sobrepasa la capacidad de muchas instituciones de salud en el tercer mundo, lo cual excluye a muchos pacientes de los beneficios descrito" e que "se describe el diseño y construcción de un equipo constituido por hardware y software para obtener los PES a un muy bajo costo con el nivel de calidad requerido".

Outro fator relevante é que náo há referência no texto para diferenças de sexo ou idade no que diz respeito ao uso do instrumento e para a leitura do sinal 
proveniente do equipamento. Rossi et al. analisaram 8 procedimentos cirúrgicos em pacientes escolióticos com ênfase no pareamento dos indivíduos justamente pela diferença de sinal elétrico encontrada em humanos $^{8,10}$; Hyun et al. ${ }^{11}$ analisaram 100 procedimentos cirúrgicos de coluna para declarar que a uniáo de técnicas melhoraria o monitoramento dos procedimentos cirúrgicos.

Do ponto de vista clínico a hipótese não está clara, tornando impossível determinar se, na prática, o equipamento seria adequado. A metodologia certamente não permite generalizar o resultado.

\section{RESULTADOS}

$\mathrm{O}$ autor afirma que "No fueron probados los demás valores de estimulación (110V, 130V y 150V)" e que "Los niveles de estimulación altos son usados en personas que poseen gran cantidad de grasa corporal por lo cual el estímulo tiene que ser mayor para producir potenciales evocados somatosensoriales visibles". Isso demonstra a necessidade de testar o instrumento em indivíduos diferentes. O próprio autor afirma que há diferença de sinal em indivíduos obesos e que o instrumento não foi testado em três valores de estimulação pelo fato do paciente ser magro. Tal fato dificulta a generalização do uso do aparelho, o que seria a justificativa prática para a realização do estudo. A massa gorda de um indivíduo possui uma impedância muito maior que a massa magra; isto significa que é muito mais difícil para a corrente fluir através dela ${ }^{12}$. Tecidos aquosos como o sangue, o músculo e o nervo tem baixa resistência ôhmica; osso e gordura tem resistência mais alta e a epiderme possui a mais elevada de todas ${ }^{2}$.

$\mathrm{O}$ autor relata que os resultados obtidos concordam com os parâmetros normais encontrados na literatura para os indivíduos que participaram do estudo. Aqui faz-se uma confusão já que apenas um (1) indivíduo participou dos testes. O Guideline da Sociedade Americana de Neurofisiologia sugere grupo controle para todos os estudos, com número mínimo de 20 indivíduos para cada grupo ${ }^{13}$.

Sugerimos testar o equipamento, no mínimo em uma mulher, um idoso(a) e um obeso(a) considerados sáos e em indivíduos com patologias que provoquem alteração do sinal a fim de verificar se o instrumento seria sensível a potenciais baixos. Parece-nos interessante ainda que hajam grupos controle pareados para todos os sujeitos testados.

Há figuras do equipamento e dos sinais produzidos por ele, mas não há dados que descrevam o posicionamento do paciente. Não foi possível usar tabelas com dados de apenas um indivíduo.

\section{DISCUSSÃO E CONCLUSÃO}

Por definição discussão é a interpretação e análise crítica dos resultados obtidos em relaçáo à metodologia utilizada. É feita a comparação dos resultados alcançados com os resultados obtidos pelos autores $\mathrm{da}$ revisão bibliográfica ${ }^{14}$. Esta definição não foi seguida pelo autor; nem mesmo as referências usadas no artigo foram aproveitadas para a discussão. Sugerimos pesquisar trabalhos práticos recentes que possam ser aproveitados nesta parte do artigo, pois a técnica não é de conhecimento geral e há mudanças constantes que podem e devem ser exploradas.

Esta é a fase do trabalho onde se apresenta concordância ou discordância de outros autores da literatura internacional com os resultados do trabalho em questão e, eventualmente, até aqueles já utilizados anteriormente na bibliografia. Podem ser estabelecidas relaçóes, deduçóes paralelas, possíveis generalizaçóes ou mesmo identificarem-se falhas de correlação. Assim seria interessante realizar-se uma exposição comentada dos resultados já relatados na seção específica para tal com linguagem clara, onde o autor se posicionaria em relação aos resultados obtidos.

A discussão deveria mostrar como o manuscrito é original em relação ao restante da literatura. Devem ser apresentadas as três ou quatro principais conclusóes do estudo para preparar os leitores para uma discussão detalhada de cada um dos pontos, mostrando diferenças e semelhanças quanto à metodologia e achados, com análise quantitativa e qualitativa em relação aos textos discutidos ${ }^{15}$. 
$\mathrm{O}$ autor finaliza o texto afirmando que o equipamento permite ao neurocirurgiáo realizar um estudo de potenciais evocados durante uma intervenção cirúrgica. Tal fato não está de acordo com o objetivo primário do trabalho e deixa questóes importantes sobre este ponto, uma vez que o equipamento em estudo não foi testado durante procedimento cirúrgico.

\section{REFERÊNCIAS}

1.Umphred DA. Reabilitação Neurológica. 4ed. São Paulo: Manole, 2004, p.901-7.

2.Low J, Reed A. Eletroterapia Explicada: Princípios e Pratica. 3a Ed. São Paulo: Manole, 2001, p.165-9.

3.Bragagnolo MAJ, Teodoro V, Lucchesi LM, Santos RF, Feldner ACCA, Ribeiro TCR, Tufik S, Kondo M. Correlação entre a amônia e o potencial evocado relacionado a eventos (P300) em pacientes cirróticos. Rev Neurocienc 2009;17:122-7.

4.Guedes MC, Weber R, Gomez MVSG, Neto RVB, Peralta CGO, Ferreira BR. Efeitos do potencial de açáo neural sobre a percepçáo de fala em usuários de implante coclear. Rev Bras Otorrinolaringol 2007;73:439-45.

5.Poloa A, Tercedora A, Paniagua-Sotob J, Acostacy F, Cañadas A. Monitorización neurofisiológica en la cirugía de escoliosis con hipotensión controlada. Rev Esp Anestesiol Reanim 2000;47:367-70.
6.Costallat LT L, Zanardi VA, Quagliato EMAB. Avaliaçäo neurofisiológica no lúpus eritematoso sistêmico. Rev Bras Reumatol 1997;37:31-6.

7.Webster JG. Encyclopedia of Medical Devices and Instrumentation. San Francisco: Wiley Intercience, 1998, p.2.

8.Deletis V. Basic methodological principles of multimodal intraoperative monitoring during spine surgeries. Eur Spine J 2007;16:S147-52.

9.Sella VRG, Nohama P, Faria RA, Scharf CA, Wolf R. Método de avaliaçấo da hipotrofia muscular por desuso empregando eletromiografia de superfície. Med Reab 2002;60:9-12.

10.Rossi L, Bianchi AM, Merzagora A, Gaggiani A, Cerutti $S$ and Bracchi F. Single trial somatosensory evoked potential extraction with ARX filtering for a combined spinal cord intraoperative neuromonitoring technique. Biomed Eng OnLine 2007;6:2.

11. Hyun SJ, Rhim SC, Kang JK, Hong SH, Park BR. Combined motorand somatosensory-evoked potential monitoring for spine and spinal cord surgery: correlation of clinical and neurophysiological data in 85 consecutive procedures. Spinal Cord 2009;47:616-22.

12.Wilmore JH, Costill DL. Fisiologia do esporte e do Exercício. 2a Ed. São Paulo: Manole, 2001, pp. 498.

13.American Society Clinical Neurophysiology. Guideline 9A: Guidelines on Evoked Potentials. J Clin Neurophysiol 2006;23:1-13.

14.Cabral JD, Silva IM, Lopes EA. Manual para elaboração de artigos científicos Unileste MG: de acordo com as normas de documentação da ABNT (endereço na Internet). Minas Gerais: Centro Universitário do Leste de Minas Gerais (atuzlizado em: 2008; citado em: 2010). Disponível em: http:// www.unilestemg.br/portal/biblioteca/downloads/manual-para-elaboracaode-artigos-cientificos.pdf

15.Pietrobon R. Templates in Manuscripts and Grand writing (endereço na internet). USA: Duke University (atualizado em: 2010; citado em: 2010). Disponivel em: www.researchonresearch.org 